\title{
O FINANCIAMENTO DO LAZER NO BRASIL PELOS DIFERENTES ENTES FEDERADOS
}

Recebido em: $13 / 03 / 2021$

Aprovado em: 15/07/2021

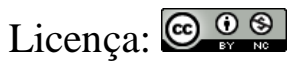

Fernando Henrique Silva Carneiro ${ }^{1}$ Instituto Federal de Educação, Ciência e Tecnologia de Goiás (IFG) - Campus Inhumas

Inhumas - GO - Brasil

Ana Elenara Pintos ${ }^{2}$

Universidade Estadual de Minas Gerais (UEMG) - Campus Ituiutaba Ituiutaba - MG - Brasil

Universidade Federal de Minas Gerais (UFMG)

Belo Horizonte $-\mathrm{MG}-$ Brasil

RESUMO: A pesquisa teve o objetivo de analisar o financiamento do lazer no Brasil pelos Municípios, Estados/Distrito Federal e União ao longo de 2013 a 2018. Esta é uma pesquisa descritivo-exploratória, de cunho quanti-qualitativo, realizada a partir de levantamento documental e análise de dados baseada no indicador magnitude do gasto. Embora o lazer seja um direito social consagrado pela Constituição Federal de 1988, há limites sob seu financiamento pelos diferentes entes federados, expressão disso é a irrisória participação do gasto da subfunção lazer no gasto orçamentário dos diferentes entes federados. Os Municípios são o principal ente federado que direcionou recursos para a subfunção lazer, sendo eles os principais promotores das políticas públicas de lazer.

PALAVRAS-CHAVE: Financiamento Público. Federalismo. Atividades de Lazer.

\section{THE FINANCING OF LEISURE IN BRAZIL BY THE DIFFERENT FEDERATED ENTITIES}

ABSTRACT: The research aimed to analyze the financing of leisure in Brazil by the Municipalities, States/Federal District and the Union from 2013 to 2018. his is a descriptive-exploratory, quantitative-qualitative research, carried out from a documentary survey and data analysis based on the magnitude of expenditure indicator. Although leisure is a social right enshrined in the Federal Constitution of 1988, there are limits on its financing by the different federated entities, an expression of this is the negligible participation of the spending of the leisure subfunction in the budgetary

\footnotetext{
${ }^{1}$ Doutor em Educação Física pela Universidade de Brasília. Docente do Instituto Federal de Goiás (IFG)

- Campus Inhumas.

2 Doutoranda em Estudos do Lazer pela Universidade Federal de Minas Gerais (UFMG). Docente da Universidade Estado de Minas Gerais (UEMG) - Campus de Ituiutaba.
} 
expenditure of the different federated entities. Municipalities are the main federated entity that directed resources to the leisure subfunction, and they are the main promoters of public leisure policies.

KEYWORDS: Public Financing. Federalism. Leisure Activities.

\section{Introdução}

A organização político-administrativa federativa é a forma do Estado brasileiro, sendo este composto de maneira autônoma por União, Estados, Distrito Federal (DF) e Municípios (BRASIL, 1988). Para Arretche (2004) o federalismo torna mais difícil a coordenação dos objetivos das políticas, gerando superposição de competências e competição entre os diferentes níveis de governo. Buscando mitigar estes desafios, a Constituição Federal de 1988 (CF 88) buscou instituir processos de descentralização dos serviços públicos básicos, definindo macrorresponsabilidades (CAVALCANTE, 2011).

A CF 88 em seu Art. 23 define competências comuns da União, dos Estados, do DF e dos Municípios para diferentes áreas, contudo dentre elas não está o lazer, este também não é apresentado como competência exclusiva de cada ente federado. Para Santos; Carvalho e Fores (2019), a falta de definição clara para o âmbito do esporte e lazer é um incentivo da federação a inação, já Santos; Starepravo e Canan (2018), apontam que há razões institucionais para esse "desordenamento", como a falta de produção de normas que orientassem o comportamento dos entes federados pós-CF 88 e uma sinalização de paralisia política na oferta de políticas públicas de esporte e lazer, haja vista o Ministério do Esporte (ME) ter sido criado apenas em 2003.

Contraditoriamente a essa falta de definição constitucional sobre a competência para realizar as políticas públicas de lazer, no Art. $6^{\circ}$ da $\mathrm{CF} 88$, o lazer é apresentado como um dos direitos sociais, no parágrafo $3^{\circ}$ do Art. 217 é apontado que o Poder Público deverá incentivar o lazer, como forma de promoção social e no Art. 227 é 
colocado que é dever da família, da sociedade e do Estado assegurar o lazer as crianças, adolescentes e jovens.

Sob o ponto de vista legal, a partir da CF 88, o lazer vem se colocando como direito em diferentes legislações, como por exemplo o Estatuto da Criança e do Adolescente (Lei no 8.069/199), o Estatuto do Idoso (Lei nº 10.741/2003) e o Estatuto da Juventude (Lei no 12.852/2013). Mas, há necessidade de avançar para além da garantia legal, havendo a materialização do lazer como necessidade humana.

O lazer é uma produção cultural humana, que estabelece relações com diversas dimensões da vida social, como a educação, o trabalho, a arte, a economia, entre outros, tornando-se parte integrante e constitutiva de cada coletividade (GOMES, 2014). Dessarte, o lazer na contemporaneidade é a expressão de determinantes econômicos, políticos, sociais e culturais produzidos pela sociedade capitalista (MASCARENHAS, 2005). Além disso, o lazer é uma prática social e um campo multidisciplinar de estudos e de intervenções que deve ser visto sob uma perspectiva mais ampliada, transversal, em rede e de forma intersetorial.

Uma das áreas que no Brasil tem estabelecido maior relação com o lazer é o esporte - este também é apontado como direito na CF 88. Há uma aproximação entre o esporte e o lazer, principalmente, no texto constitucional, entretanto, é importante reiterar que o lazer e o esporte guardam particularidades importantes que devem ser considerados na formulação de políticas públicas ${ }^{3}$ (UNGHERI, 2019).

Determinadas áreas conseguiram estabelecer sistemas nacionais, como a saúde com o Sistema Único da Saúde (SUS) - e a assistência social - com o Sistema Único da Assistência Social (SUAS) -, definindo as competências dos diferentes entes federados,

\footnotetext{
${ }^{3}$ O lazer está articulado as atividades de livre escolha, nos limites da sociedade capitalista, desenvolvidas pelas pessoas no seu tempo livre, podendo ela contemplar diferentes interesses, como: sociais, culturais, intelectuais, físico-esportivos etc. Já o esporte, além de poder ser fruído no tempo do lazer, pode ser realizado em outros contextos, como o educacional e o de alto rendimento, dimensões esta que tem suas particularidades.
} 
elemento que inexiste no âmbito do lazer. Articulado a esses elementos, embora tenham sido realizadas ao longo da primeira década do século XXI diferentes conferências para as mais diversas áreas - educação, saúde, esporte, juventude, meio ambiente etc. - não houve uma que tematizasse especificamente o lazer (SOUZA, 2012), embora o debate sobre lazer tenha sido uma temática relevante nas Conferências Nacionais do Esporte (CNE). Também embora existam diferentes Conselhos Nacionais - saúde, educação, esporte, cidades, turismo etc. -, não há um voltado ao lazer (IPEA, 2013).

A demanda por um Sistema Nacional do Esporte e Lazer esteve presente desde a I CNE, em 2004, tendo sido sua principal deliberação (CASTELAN, 2010). A II CNE, em 2006, tematizou a construção daquele, apontando no seu documento final que "O Sistema Nacional de Esporte e Lazer, tendo por base o regime de colaboração entre a união, os estados e municípios, com ênfase na municipalização, consolidando o esporte e o lazer como direitos sociais e guiando-se pelos princípios da democratização e inclusão social [...]” (MINISTÉRIO DO ESPORTE, 2006) - entretanto, o sistema não saiu do papel. Na III CNE, em 2010, embora tenha sido criado o Plano Decenal de Esporte e Lazer, seu foco foi na organização dos megaeventos esportivos, ocupando o lazer espaço marginal (FLAUSINO, 2013).

O financiamento das diferentes políticas públicas é uma discussão essencial para a materialização delas e a própria organização do Estado, com especificidades em uma federação. Em estudo realizado por Carneiro et al. (2019) sobre as diferentes fontes de financiamento público do esporte - orçamentárias, extraorçamentárias e gastos tributários -, é possível notar a presença de recursos direcionados ao lazer nestas três diferentes fontes, com destaque para os recursos orçamentários e desonerações tributárias para as entidades recreativas sem fins lucrativos. 
Em estudo realizado por Pereira et al. (2020) sobre o financiamento do esporte no periodismo brasileiro, é possível identificar que dos 43 estudos encontrados, 10 apresentam em seus títulos o termo "lazer". Destes estudos sobre o financiamento do espore e lazer, 5 analisam o orçamento (ALMEIDA; MARCHI JÚNIOR, 2010; ATHAYDE; MASCARENHAS; SALVADOR, 2015; GRASSO; ISAYAMA, 2017; SANTOS; STAREPRAVO; CANAN, 2018; SANTOS; STAREPRAVO, 2018), sendo os 2 primeiros sobre a União e os 3 últimos sobre Municípios; outros 4 estudos tematizaram o financiamento de programas específicos (PINTOS; ATHAYDE; GODOFLITE, 2017; SOARES, 2017; CARNEIRO et al., 2018; OLIVEIRA; SUASSUNA; TROMPIERI FILHO, 2013), os dois primeiros discutiram o Programa Esporte e Lazer da Cidade (PELC), o terceiro um programa do Distrito Federal e o último um programa de Fortaleza; e houve 1 estudo sobre os megaeventos (FIGUERÔA; MEZZADRI; SILVA, 2013), especificamente sobre os legados dos Jogos Rio 2016 para esporte e lazer. A maior parte dos estudos sobre o financiamento do lazer o associa ao esporte, contudo investigações que discutem exclusivamente $o$ financiamento das políticas públicas de lazer, com é o caso de Ávila e Silva (2014) e Silva; Santana e Silva (2015), enquanto o primeiro tematiza a esfera municipal, o segundo tematiza a esfera estadual.

O estudo sobre o financiamento e gasto com as políticas públicas de lazer é uma chave interpretativa importante para compreender a importância e magnitude delas. No entanto, os estudos que tem sido publicados sobre o financiamento do lazer ou do esporte e lazer no Brasil se pautam, especialmente, em análises de programas específicos ou de uma esfera da federação. Dessarte, faltam pesquisas que apresentem uma análise sobre a totalidade do financiamento do lazer pelo Estado brasileiro em suas diferentes esferas, avaliando o papel de cada uma delas. Desta forma, temos por 
objetivo analisar o financiamento do lazer no Brasil pelos Municípios, Estados/DF e União ao longo de 2013 a 2018.

\section{Metodologia}

Esta é uma pesquisa descritivo-exploratória, de cunho quanti-qualitativo, realizada a partir de levantamento documental referente ao período de 2013 a 2018 . A coleta de dados foi realizada no Sistema de Informações Contábeis e Fiscais do Setor Público Brasileiro (Siconfi) (TESOURO NACIONAL, 2020) e no Siga Brasil (SENADO FEDERAL, 2020). O primeiro foi utilizado para coletar os dados do gasto orçamentário total e do gasto das três subfunções da Função Desporto e Lazer (FDL) realizado pelos Municípios e Estados/DF, além do quantitativo populacional brasileiro; já o segundo foi usado para coletar os dados sobre o gasto orçamentário total e do gasto das três subfunções da FDL da União. O período de 2013 a 2018 ser refere ao dado mais antigo e mais recente completo presente no Siconfi.

A análise de dados tem como referência a metodologia desenvolvida por Carneiro e Mascarenhas (2018), tendo por base o indicador magnitude do gasto. De acordo com os referidos autores, este indicador está relacionado ao montante gasto ao longo do tempo, devendo ser analisado elementos como: o que demonstra a evolução da série histórica do gasto com lazer? Qual a proporção do gasto com lazer em relação ao gasto total ou ao gasto com as diferentes subfunções da FDL? Qual o gasto per capita com lazer?

Foram utilizados os recursos financeiros dos orçamentos dos Municípios, dos Estado/DF e da União, a partir da fase de liquidação, esta se refere a segunda fase da despesa orçamentária - precedida do empenho, primeira fase -, sendo o momento em 
que a unidade executora recebe o objeto do empenho, confirmando que o bem foi entregue ou o serviço foi executado.

Os dados financeiros foram deflacionados pelo Índice Geral de Preços Disponibilidade Interna (IGP-DI), calculado pela Fundação Getúlio Vargas, a partir da Calculadora do cidadão, a preços de dezembro de 2018, haja vista a necessidade de atualizar os valores para comparações longitudinais, eliminando os efeitos da inflação e da variação cambial da moeda brasileira.

\section{Apresentação e Discussão dos Dados}

Na linguagem orçamentária há a FDL que é uma rubrica que agrega o esporte e o lazer, articulada a ela há três subfunções: desporto de rendimento, desporto comunitário e lazer (MINISTÉRIO DO PLANEJAMENTO, ORÇAMENTO E GESTÃO, 1999). Não necessariamente a FDL precisa se ligar a estas três subfunções, nem estas precisam obrigatoriamente se vincular aquela. No governo federal, ao longo do tempo, diferentes funções direcionaram recursos para as três subfunções supracitadas, assim como a FDL gastou com diversas subfunções (CARNEIRO, 2018; MASCARENHAS, 2016). A partir de dados do Tesouro Nacional (2020) sobre Estados/DF e Municípios é possível identificar que a FDL também esteve ligada as subfunções administração geral e demais subfunções desporto e lazer.

Contudo, esta investigação se dará exclusivamente sobre o gasto dos diferentes entes federados com a subfunção lazer. Deste modo, na Tabela 1 são apresentados os gastos da União, Estados/DF e Municípios com a referida subfunção. 
Tabela 1: Gasto com a subfunção lazer pelos Municípios, Estados/DF e União série 2013 a 2018

\begin{tabular}{|c|c|c|c|c|c|c|c|}
\hline Esferas & 2013 & 2014 & 2015 & 2016 & 2017 & 2018 & Total \\
\hline \multirow{2}{*}{ Municípios } & $\begin{array}{c}\mathrm{R} \$ \\
644,51\end{array}$ & $\begin{array}{c}\mathrm{R} \$ \\
617,41\end{array}$ & $\begin{array}{c}\mathrm{R} \$ \\
561,99\end{array}$ & $\begin{array}{c}\mathrm{R} \$ \\
454,41\end{array}$ & $\begin{array}{c}\mathrm{R} \$ \\
366,13\end{array}$ & $\begin{array}{c}\mathrm{R} \$ \\
431,80\end{array}$ & $\mathrm{R} \$ 3.076,26$ \\
\hline & $50,74 \%$ & $77,82 \%$ & $87,46 \%$ & $83,52 \%$ & $85,73 \%$ & $88,08 \%$ & $73,82 \%$ \\
\hline \multirow[t]{2}{*}{ Estados/DF } & $\begin{array}{c}\mathrm{R} \$ \\
503,36\end{array}$ & $\begin{array}{c}\mathrm{R} \$ \\
176,01\end{array}$ & $\begin{array}{c}\mathrm{R} \$ \\
80,57\end{array}$ & $\begin{array}{c}\mathrm{R} \$ \\
89,65\end{array}$ & $\begin{array}{c}\mathrm{R} \$ \\
60,93\end{array}$ & $\begin{array}{c}\mathrm{R} \$ \\
58,42\end{array}$ & $\mathrm{R} \$ 968,93$ \\
\hline & $39,63 \%$ & $22,18 \%$ & $12,54 \%$ & $16,48 \%$ & $14,27 \%$ & $11,92 \%$ & $23,25 \%$ \\
\hline \multirow[t]{2}{*}{ União } & $\begin{array}{c}\mathrm{R} \$ \\
122,31\end{array}$ & - & - & - & - & - & $\mathrm{R} \$ 122,31$ \\
\hline & $9,63 \%$ & - & - & - & - & - & $2,93 \%$ \\
\hline Total & $\begin{array}{c}\mathrm{R} \$ \\
1.270,18\end{array}$ & $\begin{array}{c}\mathrm{R} \$ \\
793,42 \\
\end{array}$ & $\begin{array}{c}\mathrm{R} \$ \\
642,56 \\
\end{array}$ & $\begin{array}{c}\mathrm{R} \$ \\
544,06\end{array}$ & $\begin{array}{c}\mathrm{R} \$ \\
427,06 \\
\end{array}$ & $\begin{array}{c}\mathrm{R} \$ \\
490,22 \\
\end{array}$ & $\mathrm{R} \$ 4.167,51$ \\
\hline
\end{tabular}

Fonte: Tesouro Nacional (2020) e Senado Federal (2020). Elaboração própria.

Obs.: Valores liquidados. Valores deflacionados pelo IGP-DI a preços de dezembro de $2018 \mathrm{em}$ milhões de R\$ e \%.

Conforme pode ser observado, na totalidade os Municípios foram a unidade federativa que mais gastou com lazer, representando 73,82\% dos $\mathrm{R} \$ 4,17$ milhões gastos no período. Os gastos dos Estados/DF representaram 23,25\% e os da União 2,93\%. Dessarte, os Municípios brasileiros tem sido o ente federado que mais tem direcionado recursos para materialização do direito ao lazer. No âmbito da FDL, o estudo de Santos; Starepravo e Canan (2018) havia demonstrado que o gasto dos Municípios eram maiores que os da União.

Embora estudos como o de Carneiro; Athayde e Mascarenhas (2019) apontem que houve o financiamento de políticas de lazer pelo ME ao longo de 2003 a 2018, estes recursos não foram direcionados para a subfunção lazer de 2013 a 2018. Tanto que o único gasto com a subfunção lazer, em 2013, se deu pelo Ministério da Cultura com a ação de "Implantação de espaços integrados de esporte, cultura, lazer e serviços públicos (Praças dos Esportes e da Cultura)" (SENADO FEDERAL, 2020). Portanto, esse dado revela o lugar marginal das políticas públicas de lazer dentro do Ministério do Esporte no período analisado. 
Chama atenção que ao longo do tempo os recursos orçamentários do Estado brasileiro para lazer, considerando todos os entes federados, foram reduzidos, apenas em 2018 o valor foi superior ao ano anterior. Também, o valor gasto no último ano da série corresponde a apenas 38,59\% do gasto do primeiro ano. As oscilações presentes no total são reflexo direto dos gastos dos Municípios, vez que os gastos deles diminuíram de 2013 a 2017 e aumentaram em 2018. Já os recursos dos Estados/DF diminuíram de 2013 a 2015, subindo em 2016 e nova tendência de queda até 2018, contundo há uma grande variação, pois só em 2013 os Estados/DF gastaram 51,95\% de tudo que estes entes federados direcionaram ao lazer. Já a União gastou com a subfunção lazer apenas em 2013, não tendo sido registrados gastos nos demais anos da série. Portanto, os Municípios foram o ente federado que se consolidou como o principal responsável pela realização das políticas públicas de lazer.

Tendo por base a participação no gasto com lazer dos três entes federados brasileiros, buscamos identificar qual o nível de adesão de Municípios e Estados/DF ao gasto com a subfunção lazer. Assim, na Tabela 2 é possível identificar que o nível médio ao longo do tempo dos Municípios foi de 23,37\% e dos Estados/DF foi de $51,85 \%$.

Tabela 2: Nível de adesão dos Municípios e Estados/DF ao gasto com a subfunção lazer - Série 2013 a 2018

\begin{tabular}{ccccccccc}
\hline $\begin{array}{c}\text { Unidades } \\
\text { Federativas }\end{array}$ & & $\mathbf{2 0 1 3}$ & $\mathbf{2 0 1 4}$ & $\mathbf{2 0 1 5}$ & $\mathbf{2 0 1 6}$ & $\mathbf{2 0 1 7}$ & $\mathbf{2 0 1 8}$ & Média \\
\hline & Total & 27 & 27 & 27 & 27 & 27 & 27 & 27 \\
Estados/DF & Adesão & 15 & 14 & 11 & 15 & 14 & 15 & 14 \\
& Adesão (\%) & 55,56 & 51,85 & 40,74 & 55,56 & 51,85 & 55,56 & 51,85 \\
& Total & 5461 & 5190 & 5432 & 5422 & 5522 & 5452 & 5413 \\
Municípios* & Adesão & 1302 & 1254 & 1282 & 1257 & 1256 & 1236 & 1265 \\
& Adesão (\%) & 23,84 & 24,16 & 23,60 & 23,18 & 22,75 & 22,67 & 23,37 \\
\hline
\end{tabular}

Fonte: Tesouro Nacional (2020). Elaboração própria.

Obs.: *Os valores se referem ao quantitativo de Municípios que disponibilizaram seus gastos orçamentários anualmente no Siconfi. 
Embora em média a maioria dos Estados/DF tenham realizado gasto com a subfunção lazer, eles não conseguiram superar o gasto dos Municípios que contou com a adesão de menos de um quarto deste ente federado. A União teve adesão com este tipo de gasto apenas em 2013, ignorando-o a partir de 2014.

No período de 2013 a 2018, a média de adesão dos Municípios ao gastos com a FDL foi de 92,41\%, já em relação a Estados/DF e União a adesão foi de 100\% em todos os anos (TESOURO NACIONAL, 2020; SENADO FEDERAL, 2020). Desta forma, podemos compreender que há uma predileção dos diferentes entes federados por gastarem com a FDL, gasto este que não tem sido direcionado para rubrica específica da subfunção lazer. Dessarte, a possibilidade de concretização das políticas públicas de lazer acaba tendo um papel secundário no bojo das políticas públicas de esporte e lazer, expressão disso é a forma como tem se dado o gasto.

Para Santos; Carvalho e Froes (2019) a falta de definição clara sobre a responsabilidade das políticas públicas de esporte e lazer para os diferentes entes federados é um incentivo à inação, os dados das Tabelas 1 e 2 demonstram que esta tem sido a realidade no âmbito das políticas públicas de lazer. Expressão disso é que menos de um quarto dos Municípios aderem ao gasto com a subfunção lazer, dos seis anos analisados em apenas um a União gastou com esta rubrica e pouco mais da metade dos Estados realizam este gasto.

Embora os Municípios e Estados/DF sejam as unidades federativas que mais gastam com subfunção lazer, elas são as que menos tem recursos disponíveis para serem gastos com as diferentes políticas públicas. Como pode ser observado na Tabela 3, ao longo de 2013 a 2018, a União ficou com 64,28\% dos recursos públicos, os Estados/DF ficaram com 21,73\% e os Municípios com 13,99\%. 
Tabela 3: Gasto geral das unidades federativas - Séria 2013 a 2018

\begin{tabular}{ccccccccc}
\hline $\begin{array}{c}\text { Unidade } \\
\text { federativa }\end{array}$ & $\mathbf{2 0 1 3}$ & $\mathbf{2 0 1 4}$ & $\mathbf{2 0 1 5}$ & $\mathbf{2 0 1 6}$ & $\mathbf{2 0 1 7}$ & $\mathbf{2 0 1 8}$ & Total & \% \\
\hline Municípios & 573,32 & 601,99 & 632,65 & 616,74 & 588,79 & 644,76 & $3.658,26$ & 13,99 \\
Estados & 955,86 & 977,39 & 974,01 & 911,96 & 906,60 & 954,67 & $5.680,51$ & 21,73 \\
União & $2.505,04$ & $2.884,67$ & $2.914,44$ & $2.959,23$ & $2.672,17$ & $2.866,32$ & $16.801,86$ & 64,28 \\
Total & $4.034,22$ & $4.464,05$ & $4.521,10$ & $4.487,94$ & $4.167,56$ & $4.465,76$ & $26.140,63$ & 100,00 \\
\hline
\end{tabular}

Fonte: Tesouro Nacional (2020) e Senado Federal (2020). Elaboração própria.

Obs.: Valores liquidados. Valores deflacionados pelo IGP-DI a preços de dezembro de $2018 \mathrm{em}$ bilhões de $\mathrm{R} \$$ e $\%$.

Assim, a União como ente federado que fica com a maior parte dos recursos públicos arrecadados pelo Estado brasileiro, deveria ser aquele que mais gasta com a subfunção lazer, no entanto, essa não é a realidade. O protagonismo tem sido dos Municípios, mesmo sendo o ente federado que conta com os mais diminutos recursos públicos, o que reflete a numerosa quantidade de municípios sem capacidade fiscal e administrativa. Ribeiro et al. (2018) entendem que a adoção de sistema federativo de caráter centralizado no Brasil se colide com a perspectiva descentralizadora das políticas públicas, presente na $\mathrm{CF} 88$, o que compromete as funções redistributivas do Estado e sua capacidade de corrigir iniquidades.

As transferências constitucionais, através dos Fundos de Participação Estadual e Municipal (FPE e FPM) se consolidariam em mecanismo necessários a distribuição mais equânime de recursos no sentido de diminuir as desigualdades entre as unidades da federação, compensando os desequilíbrios fiscais. No entanto, diferente disso, é possível observar a presença de disputas de natureza federativa, como a "guerra fiscal" entre os Estados. Nesse sentido, a possibilidade de uma perspectiva cooperativa mais eficaz para enfrentar os dilemas decorrentes das desigualdades entre as esferas governamentais é minada pelos critérios econômico-financeiros e os conflitos de instâncias políticas (NASCIMENTO, 2001). 
Tendo por base esta discussão é importante identificarmos a magnitude do gasto da subfunção lazer das unidades federativas em relação ao seu gasto orçamentário total, elemento apresentado na Tabela 4. A média de gasto total somando tudo que foi gasto com a subfunção lazer pelos três entes federados em relação ao gasto orçamentário total do Estado brasileiro, a média foi de $0,016 \%$, sendo esta a proporção de gasto específico com as políticas públicas de lazer.

Tabela 4: Magnitude do gasto com a subfunção lazer em relação ao gasto geral das diferentes unidades federativas - Série 2013 a 2018

\begin{tabular}{cccccccc}
\hline Esferas & $\mathbf{2 0 1 3}$ & $\mathbf{2 0 1 4}$ & $\mathbf{2 0 1 5}$ & $\mathbf{2 0 1 6}$ & $\mathbf{2 0 1 7}$ & $\mathbf{2 0 1 8}$ & Média \\
\hline Municípios & 0,112 & 0,103 & 0,089 & 0,074 & 0,062 & 0,067 & 0,084 \\
Estados & 0,053 & 0,018 & 0,008 & 0,010 & 0,007 & 0,006 & 0,017 \\
União & 0,005 & 0,000 & 0,000 & 0,000 & 0,000 & 0,000 & 0,001 \\
Total & 0,031 & 0,018 & 0,014 & 0,012 & 0,010 & 0,011 & 0,016 \\
\hline
\end{tabular}

Fonte: Tesouro Nacional (2020) e Senado Federal (2020). Elaboração própria.

Obs.: Valores liquidados em $\%$.

Contudo, enquanto a média de gasto dos Municípios foi de $0,084 \%$, a de Estados/DF foi de $0,017 \%$ e da União foi de $0,001 \%$. Isto revela que o gasto com as políticas públicas de lazer pelo Estado brasileiro ocupa um lugar marginal. Isso é ratificado pelos dados da Tabela 5, que apresentam a proporção de gasto da subfunção lazer em relação as subfunções vinculadas à FDL das diferentes unidades federativas.

Tabela 5: Magnitude do gasto com a subfunção lazer em relação as subfunções vinculadas à FDL das diferentes unidades federativas - Série 2013 a 2018

\begin{tabular}{cccccccc}
\hline Esferas & $\mathbf{2 0 1 3}$ & $\mathbf{2 0 1 4}$ & $\mathbf{2 0 1 5}$ & $\mathbf{2 0 1 6}$ & $\mathbf{2 0 1 7}$ & $\mathbf{2 0 1 8}$ & Média \\
\hline $\begin{array}{c}\text { Município } \\
\text { s }\end{array}$ & 15,79 & 13,46 & 11,06 & 11,10 & 12,36 & 13,44 & 12,87 \\
$\begin{array}{c}\text { Estados/D } \\
\quad \text { F }\end{array}$ & 8,77 & 5,38 & 7,05 & 9,81 & 7,17 & 5,98 & 7,36 \\
União & 22,53 & 0,00 & 0,00 & 0,00 & 0,00 & 0,00 & 3,75 \\
Total & 12,26 & 8,99 & 9,29 & 10,03 & 10,63 & 11,20 & 10,40 \\
\hline
\end{tabular}

Fonte: Tesouro Nacional (2020) e Senado Federal (2020). Elaboração própria.

Obs.: Valores liquidados em $\%$.

Dessarte, a magnitude média do gasto da subfunção lazer em relação as outras as subfunções vinculadas à FDL - desporto de rendimento, deporto comunitário, administração geral e demais subfunções desporto e lazer - no Estado brasileiro foi de 
10,40\%. Mais uma vez o destaque são os Municípios (12,87\%), em seguida os Estados/DF (7,36\%) e, por último, a União (3,75\%). Assim, o gasto com lazer fica subsumido ao segundo plano mesmo dentro das subfunções ligadas a FDL.

Nas três CNEs que foram realizadas há em seus documentos finais propostas de vinculação de recursos para o esporte e o lazer, isto é, recursos orçamentários que deveriam ser garantidos à área - para que isso fosse realizado, era necessária a aprovação de emenda constitucional. As deliberações da I CNE (2004) e da II CNE (2006) foram que 1\% do orçamento da União, dos Estados/DF e dos Municípios fosse para o esporte e o lazer (MINISTÉRIO DO ESPORTE, 2004; 2006), já na III CNE (2010) a deliberação foi por vinculação de no mínimo $2 \%$ do orçamento da União, $1,5 \%$ dos Estados/DF e 1\% dos Municípios para o esporte e o lazer (MINISTÉRIO DO ESPORTE, 2010). Contudo, não houve aprovação de emenda constitucional com as definições propostas nas CNEs.

Estudos como os de Carneiro; Athayde e Mascarenhas (2019), Carneiro (2018) e Mascarenhas (2016), que analisaram o financiamento federal do esporte e do lazer, destacaram os diminutos gastos da União com a FDL, ficando longe de cumprir as deliberações das CNEs. Há consenso nestas pesquisas dentre outros fatores que explicam essa diminuta participação da FDL estão a falta de reconhecimento da área como um direito importante, perdendo espaço na disputa pelo orçamento, e o contingenciamento de recursos que ocorreu ao longo do tempo para gerar superávit primário, recurso voltado, principalmente, para pagamento de juros, encargos e amortizações da dívida pública. Carneiro (2018) argumenta que este processo de contingenciamento afeta, sobretudo, as funções orçamentárias que não têm gastos obrigatórios ou vinculados, caso do esporte e do lazer em que a maioria dos recursos não são vinculados (CARNEIRO et al., 2019). 
Se no bojo da FDL os gastos do Estado brasileiro ficaram longe de atingir o que estabelecia as CNEs, ao se pensar exclusivamente nas políticas públicas de lazer este lugar foi ainda mais marginalizado, elemento confirmado pelo seu papel no total gastos pelas diferentes subfunções ligadas à FDL, conforme Tabela 5. Isto é um reflexo da falta de reconhecimento social e da posição que estes setores ocupam na esfera dos direitos de cidadania (CARNEIRO, 2018).

O órgão responsável pela política pública de esporte e de lazer nacional ao longo de 2003 a 2018 foi o ME, tendo sido este o responsável pelo gasto com a FDL pela União. Todavia, a União e o ME não foram protagonistas no gasto com a FDL, seja quando comparado com os gastos de Estados/DF e Municípios, ou mesmo quando comparado com gasto orçamentário total da União. Conforme ponderam Carneiro; Athayde e Mascarenhas (2019), se a existência de Ministério exclusivo para o esporte não foi capaz de garantir montantes expressivos de recursos para o setor, com a transformação do ME em Secretaria Especial do Esporte e a implantação de uma política econômica de austeridade, espera-se que a área tenha menor representatividade no orçamento da União. Como vimos na Tabela 1, mesmo com o ME não houve recurso destinado à subfunção lazer a partir de 2014, isto é, as políticas públicas voltadas ao lazer pela União já estavam marginalizadas dentro da referida pasta.

Outra questão importante sobre a magnitude do gasto com lazer é seu gasto per capita. Na Tabela 6 é possível notar que a média de gasto do Estado brasileiro per capita com lazer foi de $\mathrm{R} \$ 3,42$. Pode ser notado que juntando os recursos da União, Estados/DF e Municípios gastos com lazer de 2013 a 2017 houve diminuição do gasto per capita, com aumento em 2018. Embora a população brasileira tenha saído de 201.032.714 habitantes, em 2013, para 206.081.432 habitantes, em 2018, isso não se refletiu em aumento do gasto com lazer. Assim, mesmo que a população brasileira 
tenho aumentado 2,51\% de 2013 a 2018, o gasto com a subfunção lazer diminuiu $61,41 \%$ entre estes anos.

Tabela 6: O gasto per capita com a subfunção lazer - Série 2013-2018

\begin{tabular}{lcccccccc}
\hline \multicolumn{1}{c}{ Esferas } & $\begin{array}{c}\text { Estados/ } \\
\text { Municípios }\end{array}$ & $\mathbf{2 0 1 3}$ & $\mathbf{2 0 1 4}$ & $\mathbf{2 0 1 5}$ & $\mathbf{2 0 1 6}$ & $\mathbf{2 0 1 7}$ & $\mathbf{2 0 1 8}$ & Média \\
\hline $\begin{array}{l}\text { União, } \\
\text { Estados/DF e } \\
\text { Municípios }\end{array}$ & - & 6,32 & 3,91 & 3,17 & 2,66 & 2,07 & 2,38 & 3,42 \\
\multicolumn{1}{c}{ Estados* } & $\begin{array}{c}\text { Ceará } \\
\text { Rio de }\end{array}$ & 29,31 & 2,13 & 0,68 & 0,57 & 0,74 & 0,87 & 5,72 \\
& $\begin{array}{c}\text { Janeiro } \\
\text { Minas } \\
\text { Gerais }\end{array}$ & 6,38 & 1,60 & 1,62 & 3,27 & 1,20 & 0,52 & 2,43 \\
& $\begin{array}{c}\text { Presidente } \\
\text { Prudente } \\
\text { Municípios** }\end{array}$ & 97,91 & 103,92 & 109,52 & 88,24 & 86,52 & 85,21 & 95,22 \\
& $\begin{array}{c}\text { Rio Claro } \\
\text { (SP) }\end{array}$ & 87,64 & 94,72 & 72,14 & 59,10 & 48,95 & 58,53 & 70,18 \\
& $\begin{array}{c}\text { São Paulo } \\
\text { (SP) }\end{array}$ & 9,49 & 7,36 & 6,47 & 0,00 & 2,16 & 0,00 & 4,25 \\
\hline
\end{tabular}

Fonte: Tesouro Nacional (2020) e Senado Federal (2020). Elaboração própria.

Obs.: Valores liquidados. Valores deflacionados pelo IGP-DI a preços de dezembro de $2018 \mathrm{em}$ $\mathrm{R} \$$. *Refere-se aos três Estados que mais gastam com a subfunção lazer. ** Refere-se aos três Municípios que mais gastam com a subfunção lazer.

São apresentados na Tabela 6 os 3 Estados e os 3 Municípios que mais gastaram com a subfunção lazer de 2013 a 2018, sendo apontado os gastos per capita com lazer pelos seis entes federados. É possível notar que estes seis entes federados tiveram uma tendência de queda nos valores gastos com lazer quando comparado 2018 com 2013. Em relação aos três Estados que mais gastaram com lazer apenas o Ceará teve média maior que a média de gasto per capita da União, Estados/DF e Municípios, Rio de Janeiro e Minas Gerais ficaram abaixo. O mesmo não acontece com os três Municípios que mais gastaram com lazer, isto é, Presidente Prudente (SP), Rio Claro (SP) e São Paulo (SP) tiveram médias maiores que a média per capita da União, Estados/DF e Municípios.

A diferença entre o gasto per capita de Presidente Prudente (SP) e Rio Claro (SP) em relação a São Paulo (SP) e os outros Estados que mais gastaram com lazer é enorme. São Paulo (SP) foi o Município brasileiro que mais gastou com a subfunção 
lazer no período ( $\mathrm{R} \$ 302,67$ milhões), contudo, quando seu gasto é relativizado à população do Município seus valores per capita se tornam diminutos. Chama atenção que os Municípios que mais gastaram com lazer estão situados no Estado de São Paulo que é o Estado mais desenvolvido economicamente. Também é importante notar na Tabela 6 a falta de continuidade do gasto com lazer, expressão disse é o Ceará ter gasto per capita com lazer de $\mathrm{R} \$ 29,31$ (2013) e $\mathrm{R} \$ 0,57$ (2016) e também São Paulo (SP) ter anos - 2016 e 2018 - que não gastou com a subfunção lazer.

\section{Considerações Finais}

A implementação de políticas públicas no Brasil sofre a influência de determinantes históricos, geográficos e socioculturais. Para lidar com as diferenças regionais, uma das saídas encontradas na CF 88 foi dar autonomia aos Municípios e Estados/DF, estabelecendo uma relação entre democracia, descentralização e autonomia política. No entanto, determinadas áreas de políticas públicas conseguiram articular a construção de sistemas nacionais, deixando clara as atribuições de cada ente federado, além de garantir financiamento, como é o caso da saúde e da assistência social.

Embora o lazer tenha sido consagrado na CF 88 como um direito social, não há um sistema nacional que o abarque ou mesmo definições sobre as atribuições dos entes federados, impactando na implementação de políticas públicas de lazer.

Os dados apresentados revelam que embora os Municípios sejam o ente federado com menos recursos para gastar com as diferentes políticas públicas, são eles que mais gastam com a subfunção lazer. Além disso, proporcionalmente ao orçamento geral, também são os Municípios o ente federado que mais gasta com lazer, o mesmo se dá em relação ao gasto das demais subfunções vinculadas à FDL. Esse protagonismo dos Municípios acontece mesmo apenas em média 23,37\% deles terem efetuado gasto para a subfunção lazer. 
Em relação aos Estados/DF, pouco mais da metade deles $(51,85 \%)$ aderiram ao gasto com a subfunção lazer. Os Estados/DF foram o ente federado que ficaram entre os Municípios e a União em relação aos gastos e a proporção de gasto em relação ao orçamento. A União, foi o ente federado que menos gasto teve com lazer, embora seja o ente federado que tem mais recursos para serem gastos com as políticas públicas. $\mathrm{Na}$ maioria dos anos - 2014 a 2018 - a União negligenciou o gasto com lazer, elemento que também se fez presente em média em 76,63\% dos Municípios e 48,15\% dos Estados.

Assim, os dados revelam uma relação inversamente proporcional entre o quantitativo de recursos públicos para as políticas públicas e o gasto com a subfunção lazer, pois a União tem mais recursos, mas foi a que menos gastou com lazer, e os Municípios são os que tem menos recursos, entretanto foram os que mais gastaram com lazer. Ademais, embora a população brasileira tenha aumentado de 2013 para 2018, o mesmo não ocorreu com os recursos da subfunção lazer, que apresentaram uma tendência de queda.

Assim, esta investigação buscou fazer uma análise de totalidade sobre o gasto com subfunção lazer pelo Estado federativo brasileiro, demonstrando o peso de cada um dos entes federados no seu gasto. As políticas públicas de lazer apresentam um caráter fortemente intersetorial, isto é, em que diferentes áreas intervêm sobre ele, assim um dos limites da investigação é ter trabalhado apenas com os gastos da subfunção lazer. Contudo, a presença difusa de gasto com as políticas públicas de lazer em diferentes funções e subfunções não possibilita que sejam identificados claramente estes gastos nas mesmas. Também, é importante que novos estudos busquem ter esse olhar de totalidade, compreendendo as desigualdades profundas no acesso ao lazer, sendo a compreensão do seu gasto um elemento importante para esta análise. Também, estudos 
que demonstrem esta realidade contribuirão significativamente para que tenhamos instrumentos de luta na busca por materializar o lazer como direito.

\section{REFERÊNCIAS}

ALMEIDA, Bárbara Schausteck de; MARCHI JÚNIOR, Wanderley. O financiamento dos programas federais de esporte e lazer no Brasil (2004 a 2008). Movimento, Porto Alegre, v. 16, n. 4, p. 72-92, 2010. Disponível em: http://seer.ufrgs.br/Movimento/article/view/13103/10845. Acesso em: 15 nov. 2020.

ARRETCHE, Marta. Federalismo e políticas sociais no Brasil: problemas de coordenação e autonomia. São Paulo em Perspectiva, São Paulo, v. 18, n. 2, p. 17-26, 2004. Disponível em: http://www.scielo.br/pdf/spp/v18n2/a03v18n2.pdf . Acesso em: 15 nov. 2020.

ATHAYDE, Pedro; MASCARENHAS, Fernando; SALVADOR, Evilásio. Primeiras aproximações de uma análise do financiamento da política nacional de esporte e lazer no Governo Lula. Revista Brasileira de Ciencias do Esporte, Florianópolis, v. 37, n. 1, p. 2-7, 2015. Disponível em: http://www.scielo.br/pdf/rbce/v37n1/0101-3289-rbce37-01-0002.pdf. Acesso: 15 nov. 2020.

ÁVILA, Temístocles Damasceno; SILVA, Marco Marco. Análise da estrutura administrativa e financeira destinada ao lazer no município de Jequié/BA. Coleção Pesquisa em Educação Física, São Paulo, v. 13, n. 1, p. 31- 40, 2014. Disponível em: https://www.fontouraeditora.com.br/periodico/upload/artigo/1085_1503948917.pdf.

Acesso: 15 nov. 2020.

BRASIL. Constituição Federal de 1988. Promulgada em 5 out. 1988. Disponível em: http://www.planalto.gov.br/ccivil_03/constituicao/constituicao.htm. Acesso em: 14 abr. 2020.

Lei $\mathbf{n}^{\circ}$ 8.069, de 13 de julho de 1990. Dispõe sobre o Estatuto da Criança e do Adolescente. $\quad$ Brasília, $1990 . \quad$ Disponível em: http://www.planalto.gov.br/ccivil_03/leis/18069.htm. Acesso em: 12 mar. 2021.

Lei $n^{0}$ 10.741, de 1 de outubro de 2003. Dispõe sobre o Estatuto do Idoso e dá outras providências. Diário Oficial da União. Brasília, 2003. Disponível em: http://www.planalto.gov.br/ccivil_03/Leis/2003/L10.741htm. Acesso em: 12 mar. 2021.

Lei $\mathbf{n}^{\mathbf{0}}$ 12.852, de 5 de agosto de 2013. Dispõe sobre os direitos dos jovens, os princípios e diretrizes das políticas públicas e juventude e o Sistema Nacional de Juventude (SINAJUVE), dentre outras orientações legais. Brasília, 2013. Disponível em: http://www.planalto.gov.br/ccivil_03/_ato2011-2014/2013/lei/112852.htm. Acesso em: 12 mar. 2021.

CARNEIRO, Fernando Henrique Silva et al. A matriz de financiamento público federal do esporte no Brasil. Revista Brasileira de Ciência e Movimento, Brasília, v. 27, n. 4, 
2019. Disponível em: https://portalrevistas.ucb.br/index.php/RBCM/article/view/10166. Acesso em: 15 nov. 2020.

O financiamento do esporte no Brasil : aspectos da atuação estatal nos governos Lula e Dilma. 2018. Tese (Doutorado em Educação Física) - Universidade de Brasília, Brasília, 2018. Disponível em: https://repositorio.unb.br/handle/10482/34067. Acesso em: 15 nov. 2020.

et al. Os Centros Olímpicos do Distrito Federal: um caso de desresponsabilização do Estado e descentralização das políticas de esporte e lazer em direção ao "terceiro setor". Licere, Belo Horizonte, v. 21, n. 2, p. 136-169, 2018. Disponível em: https://periodicos.ufmg.br/index.php/licere/article/view/1813/1230. Acesso em: 15 nov. 2020.

; ATHAYDE, Pedro Fernando Avalone; MASCARENHAS, Fernando. Era uma vez um Ministério do esporte...: seu financiamento e gasto nos governos Lula, Dilma e Temer. Motrivivência, Florianópolis, v. 31, n. 60, p. 01-22, 24 set. 2019. Disponível em: $\quad$ https://periodicos.ufsc.br/index.php/motrivivencia/article/view/21758042.2019e65541/41745. Acesso em: 15 nov. 2020.

; MASCARENHAS, Fernando. O financiamento esportivo brasileiro: proposta de metodologia crítica de análise. E-Legis, n. especial, p. 119-140, 2018. Disponível em: http://e-legis.camara.leg.br/cefor/index.php/e-legis/article/view/481/479. Acesso em: 15 nov. 2020.

CASTELAN, Lia Polegato. As Conferências Nacionais do Esporte na configuração da política esportiva e de lazer no governo Lula (2003-2010). 2010. Dissertação (Mestrado em Educação Física) - Universidade de Campinas, Campinas, 2010. Disponível em: http://repositorio.unicamp.br/jspui/handle/REPOSIP/274714. Acesso em: 15 nov. 2020.

CAVAlCANTE, Pedro. Descentralização de políticas públicas sob a ótica neoinstitucional: uma revisão de literatura. Rev. Adm. Pública, Rio de Janeiro, v. 45, n. 6, p. 1781-1804, 2011. Disponível em: https://www.scielo.br/pdf/rap/v45n6/a08v45n6.pdf. Acesso em: 15 nov. 2020.

FIGUERÔA, Katiuscia Mello; MEZZADRI, Fernando Marinho; SILVA, Marcelo Moraes. Rio 2016: possibilidades e desafios para o esporte brasileiro. Motrivivência, Florianópolis, n. 41, p. 140-154, dez. 2013. Disponível em: https://periodicos.ufsc.br/index.php/motrivivencia/article/view/21758042.2013v25n41p140/25832. Acesso em: 15 nov. 2020.

FLAUSINO, Michelle da Silva. Plano decenal: as políticas públicas de esporte e lazer em jogo. 2013. Dissertação (Mestrado em Educação Física) - Universidade de Brasília, Brasília, 2013. Disponível em: https://repositorio.unb.br/handle/10482/13744. Acesso em: 15 nov. 2020.

GOMES, Christianne Luce. Lazer: Necessidade humana e dimensão da cultura. Revista Brasileira de Estudos do Lazer, Belo Horizonte, v. 1, n. 1, p. 3-20, 2014. Disponível em: https://periodicos.ufmg.br/index.php/rbel/article/view/430/279. Acesso em: 15 nov. 2020. 
GRASSO, Rita Peloso; ISAYAMA, Hélder Ferreira. Financiamento e políticas públicas de esporte e lazer: uma análise da gestão no município de Santarém/PA (2005-2012). Revista Brasileira de Ciência e Movimento, Brasília, v. 25, n. 1, p. 151-167, 2017. Disponível em: https://portalrevistas.ucb.br/index.php/RBCM/article/view/7121/pdf_1. Acesso em: 15 nov. 2020.

IPEA. Conselhos Nacionais Perfil e atuação dos conselheiros - Relatório de Pesquisa. $2013 . \quad$ Disponível em: https://www.ipea.gov.br/participacao/images/pdfs/relatoriofinal_perfil_conselhosnacion ais.pdf. Acesso em: 6 jul. 2020.

MASCARENHAS, Fernando. O orçamento do esporte: aspectos da atuação estatal de FHC a Dilma. Revista Brasileira de Educação Física e Esporte, São Paulo, v. 30, n. 4, p. 963-980, 2016. Disponível em: https://www.scielo.br/pdf/rbefe/v30n4/1807-5509rbefe-30-04-0963.pdf. Acesso em: 15 nov. 2020.

Entre o ocio e o negocio: teses acerca da anatomia do lazer. 2005. Tese (doutorado) - Universidade Estadual de Campinas, Faculdade de Educação Fisica, Campinas, SP. Disponível em: http://repositorio.unicamp.br/jspui/handle/REPOSIP/274935. Acesso em: 15 nov. 2020.

MINISTÉRIO DO ESPORTE. Documento final - I Conferência Nacional do Esporte. Brasília, 2004. Disponível em: http://www2.esporte.gov.br/conferencianacional/conferencia1/documentoFinal.jsp. Acesso em: 01 mai. 2020.

Disponível

Documento final - II Conferência Nacional do Esporte. Brasília, 2006. http://www2.esporte.gov.br/conferencianacional/conferencia2/documentoFinal.jsp. Acesso em: 01 mai. 2020.

Documento final - III Conferência Nacional do Esporte. Brasília, 2010. Disponível em: http://www2.esporte.gov.br/conferencianacional/conferencia3.jsp. Acesso em: 01 mai. 2020.

MINISTÉRIO DO PlANEJAMENTO, ORÇAMENTO E GESTÃO. Portaria $\mathbf{n}^{\mathbf{4}} \mathbf{4 2}$, de 14 de abril de 1999. Brasília, 1999. Disponível em: http://www.orcamentofederal.gov.br/orcamentos-anuais/orcamento1999/Portaria_Ministerial_42_de_140499.pdf/. Acesso em: 18 out. 2020.

NASCIMENTO, Vânia Barbosa do. Interdependência e autonomia na gestão pública da saúde. Lua Nova, São Paulo, n. 52, p. 29-69, 2001. Disponível em: https://www.scielo.br/pdf/ln/n52/a03n52.pdf. Acesso em: 15 nov. 2020.

OLIVEIRA, Ana Amélia Neri; SUASSUNA, Dulce Maria filguiera de Almeida; TROMPIERI FILHO, Nicolino. Do direito ao lazer: o princípio acesso no Programa Esporte na Comunidade (Fortaleza-CE). Licere, Belo Horizonte, v. 16, n. 4, p. 1-20, 2013. Disponível em: https://periodicos.ufmg.br/index.php/licere/article/view/665/466. Acesso em: 15 nov. 2020.

PEREIRA, Claudia Catarino et al. O financiamento do esporte no periodismo científico brasileiro : uma revisão sistemática. Motrivivência, Florianópolis, v. 32, n. 62, p. 1-22, 
https://periodicos.ufsc.br/index.php/motrivivencia/article/view/2175-

8042.2020e64906/43409. Acesso em: 15 nov. 2020.

PINTOS, Ana Elenara; ATHAYDE, Pedro Fernando Avalone; GODOFLITE, Marliese. Municipalização do esporte e do lazer. Licere, Belo Horizonte, v. 20, n. 3, p. 424-448, 2017. https://periodicos.ufmg.br/index.php/licere/article/view/1699/1182. Acesso em: 15 nov. 2020.

RIBEIRO, José Mendes et al. Federalismo e políticas de saúde no Brasil: características institucionais e desigualdades regionais. Ciência \& Saúde Coletiva, Rio de Janeiro, v. 23, n.6, p. 1777-1789, jun. 2018. Disponível em: https://www.scielo.br/pdf/csc/v23n6/1413-8123-csc-23-06-1777.pdf. Acesso em: 15 nov. 2020.

SANTOS, Edmilson Santos dos; CARVALHO, Maria José; FROES, Georse Sousa. Investimento na Função Desporto e Lazer (FDL) por parte dos municípios dos estados do Acre, Amapá, Rondônia e Roraima. Rev. Intercon. Gest. Desport., Niterói, v. 9, n. 2, p. 1-16, 2019. Disponível em: http://revista.universo.edu.br/index.php?journal=gestaoesportiva\&page $=$ article $\& o p=v i e$ wArticle\&path\%5B\%5D=7991. Acesso em: 15 nov. 2020.

; STAREPRAVO, Fernando. Estrutura político-adminsitrativa dos governos municipais do Piauí e investimento no esporte e no lazer. Licere, Belo Horizonte, v. 21, n. 4 2018. Disponível em: https://periodicos.ufmg.br/index.php/licere/article/view/1935/1289. Acesso em: 15 nov. 2020.

; __ _ _ CANAN, Felipe. Evolução das despesas da função desporto e lazer (FDL) dos municípios do estado do Piauí de 2003 a 2011. Motrivivência, Florianópolis, v. 30, n. 55, p. 20-33, 2018. Disponível em: https://periodicos.ufsc.br/index.php/motrivivencia/article/view/21758042.2018v30n55p20/37570. Acesso em: 15 nov. 2020.

SENADO FEDERAL. Siga Brasil - Orçamento Federal. 2020. Disponível em: https://www12.senado.leg.br/orcamento/sigabrasil. Acesso em: 10 abr. 2020.

SILVA, Temístocles Damasceno; SANTANA, Tiago Almeida de; SILVA, Ricardo Correia da. O planejamento e a estrutura financeira das políticas públicas de lazer no estado da Bahia. Coleção Pesquisa em Educação Física, São Paulo, v. 14, n. 4, p. 121130, $2015 . \quad$ Disponível em: https://www.fontouraeditora.com.br/periodico/upload/artigo/1214_1505234514.pdf. Acesso em: 15 nov. 2020.

SOARES, José Montanha. O Programa Esporte e Lazer da Cidade nos planos plurianuais do governo federal: o "estresse esportivo" do PELC. Licere, Belo Horizonte, v. 20, n. 3, p. 102-138, 2017. Disponível em: https://periodicos.ufmg.br/index.php/licere/article/view/1687/1171. Acesso em: 15 nov. 2020. 
SOUZA, Clóvis Henrique Leite de. A que vieram as conferências nacionais? Uma análise dos objetivos dos processos realizados entre 2003 e 2010. Texto para discussão. IPEA: Rio de Janeiro, 2012. Disponível em: https://repositorio.ipea.gov.br/bitstream/11058/1231/1/TD_1718.pdf. Acesso em: 6 jul. 2020.

\section{TESOURO NACIONAL. Sistema de Informações Contábeis e Fiscais do Setor Público Brasileiro $\quad$ (Siconfi). $2020 . \quad$ Disponível} em: https://siconfi.tesouro.gov.br/siconfi/pages/public/consulta_finbra/finbra_list.jsf. Acesso em: 10 abr. 2020.

UNGHERI, B. O. Políticas sociais de esporte e lazer: institucionalização e municipalização no contexto do Programa Esporte e Lazer da Cidade. Licere, Belo Horizonte, v. 22, n. 2, $2019 . \quad$ Disponível em: http://periodicos.ufmg.br/index.php/licere/article/view/13585/10769. Acesso em: 15 nov. 2020.

\section{Endereço dos(as) Autores(as):}

Fernando Henrique Silva Carneiro

Endereço Eletrônico: fernandohenriquesc@gmail.com

Ana Elenara Pintos

Endereço Eletrônico: aelenara @gmail.com 